\title{
Современное состояние поддержки периферийного сканирования отечественной электронной компонентной базой
}

\author{
А. Иванов ${ }^{1}$
}

УДК 621.3.049.77::004.3'12 | ВАК 05.27.01

\begin{abstract}
В статье приводится обзор состояния поддержки отечественной ЭКБ стандарта периферийного сканирования IEEE 1149.1, позволяющего значительно упростить тестирование и диагностику производимых электронных цифровых изделий, повысить их надежность.
\end{abstract} Рассматриваются существующие проблемы и препятствия при внедрении технологии, а также пути их преодоления.

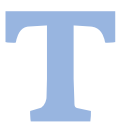

ехнология периферийного (граничного) сканирования цифровых плат для их диагностики существует уже 30 лет с момента появления первой редакции стандарта периферийного сканирования IEEE 1149.1. За прошедшее время данный стандарт претерпел несколько редакций; кроме того, появились дочерние стандарты, из которых сегодня наиболее широко используется IЕEЕ 1149.6 - стандарт периферийного сканирования для тестирования высокоскоростных цифровых связей

Суть технологии периферийного сканирования заключается в том, что если на объект тестирования (далее - ОТ) монтируется одна или несколько микросхем, поддерживающих стандарт группы IEEE 1149.x, то можно провести его тестирование и диагностирование дефектов с точностью до отдельных цепей и выводов компонентов без необходимости записи специализированных микропрограмм в запоминающие устройства платы. Достигается это за счет того, что микросхемы, поддерживающие стандарты группы IEEE 1149.х, имеют сдвиговый регистр данных (называемый также регистром периферийного сканирования), ячейки которого подключены к физическим выводам микросхемы. Последовательности данных, называемые тестовыми векторами, загружаются в регистр данных и извлекаются из него фронтами импульсов тактовой частоты по интерфейсу JTAG, который также описан в стандарте IEEE 1149.1.

Указанные выше тестовые последовательности могут диагностировать и выводить информацию о дефектах сборки ОТ (отсутствие пайки, короткие замыкания, замыкания сигналов на шины питания и земли, перепутывания проводников и т. п.) вне зависимости от

Представительство JTAG Technologies B. V., alexey@jtag.com. плотности монтажа печатного узла и используемых типов корпусов, даже таких как BGA, CSP, РоР и т. д. Для полноценного охвата ОТ тестами необходима поддержка стандарта периферийного сканирования центральными (управляющими) компонентами платы: микропроцессорами, ПлИС, микроконтроллерами, контроллерами сложных интерфейсов. Такие устройства, как ОзУ и ПзУ, тестируются за счет контакта с микросхемами, поддерживающими стандарт.

Технология периферийного сканирования активно используется российскими предприятиями радиоэлектронной промышленности на протяжении многих лет для тестирования собранных цифровых плат. В результате сокращается время и трудозатраты на создание тестов, на проверку опытных образцов и серийных изделий, уменьшается парк используемого на всех этапах измерительного оборудования, сокращаются отказы приборов в процессе эксплуатации. Добавим, что в последнее время наметилась тенденция использования этой технологии и для структурного тестирования микросборок и входного контроля микросхем на предмет дефектов разварки или контрафактного происхождения. Отдельно можно отметить преимущество периферийного сканирования при диагностике изделий особого назначения в условиях климатических испытаний, после процедур влагозащиты и, дистанционно, во время их эксплуатации.

Импортная компонентная база традиционно поддерживала стандарт IEEE 1149.1 с начала 1990-х годов. Соответственно, для плат с импортными управляющими компонентами все указанные выше задачи успешно решались - при том, однако, условии, что они проектировались с соблюдением правил тестопригодной разработки для периферийного сканирования, как то: 
доступ к JTAG-интерфейсу, доступ микросхем с поддержкой сканирования к периферии для ее тестирования ит.д.

Что касается отечественной компонентной базы, то она за последние пять лет сделала большой скачок в плане поддержки периферийного сканирования. Мы провели исследование рынка российской ЭКБ в части микропроцессоров, Плис, микроконтроллеров и сложных СБИС других типов на предмет поддержки периферийного сканирования. В качестве инструментов для изучения состояния дел использовались опросы российских предприятий, разрабатывающих ЭКБ или применяющих ее, а также верификация собственными силами с использованием специализированных программно-аппаратных средств корректности работы периферийного сканирования.

Следует отметить положительное отношение и повышенный интерес потребителей ЭКБ к подобному исследованию, так как приборостроителей в большой степени волнует возможность автоматизированного тестирования их продукции. Централизованно такая работа в Российской Федерации не велась. Общие (без указания конкретных наименований микросхем) данные по состоянию исследования на апрель 2020 года приведены в табл. 1.
Отметим, что перечень компаний, приведенных в табл. 1, не включает всех разработчиков цифровой ЭКБ (разработчиков аналоговой ЭКБ ввиду неактуальности для нее темы статьи мы не рассматриваем) - их в России значительно больше; но данных по поддержке стандарта IEEE 1149.1 от других разработчиков мы не получили.

В ряду приведенных в табл. 1 компаний стоит выделить $A О$ «ПКК «Миландр", где, помимо наличия широкой линейки микросхем с поддержкой периферийного сканирования, реализован также профессиональный программно-аппаратный комплекс верификации регистров периферийного сканирования в новых микросхемах, единственный в Российской Федерации на сегодняшний день. Наибольшее количество микросхем с поддержкой IEEE 1149.1 имеется в ассортименте ПКК "Миландр", НИИСИ РАН, МЦСТ. Отметим, что реализация регистров по стандарту IEEE 1149.1 при проектировании микросхем это стандартная функция автоматизированных САПР для микроэлектроники.

Внедрение периферийного сканирования по стандартам IEEE 1149.x носит инициативный характер. Можно сказать, что некоторую, впрочем, незначительную роль играет конкуренция, но она слаба ввиду сохранения монополии многих предприятий-разработчиков на импортозамещение отдельных видов ЭКБ. В большей степени

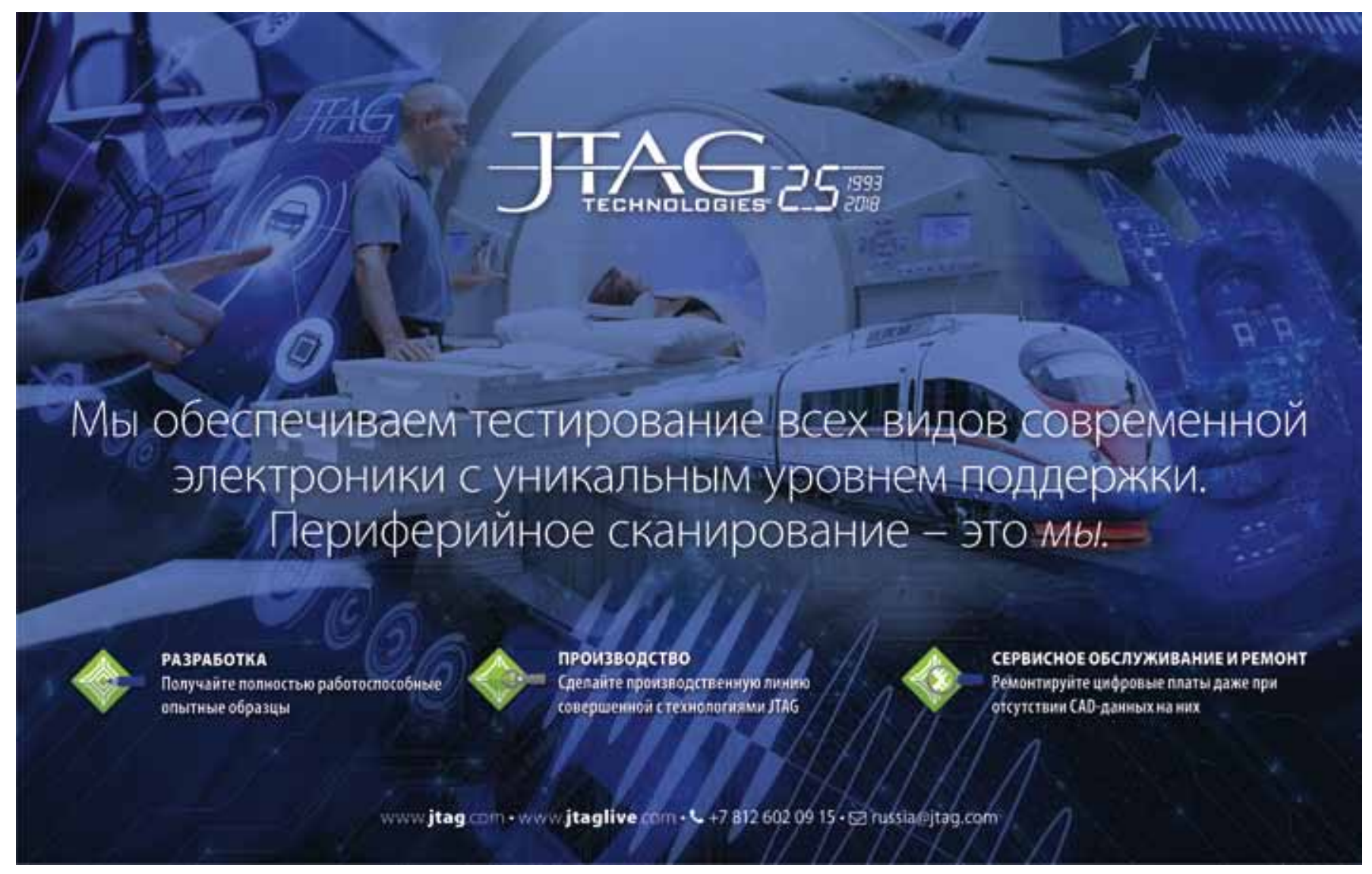


Таблица 1. Состояние поддержки периферийного сканирования российской электронной компонентной базой

\begin{tabular}{|c|c|c|c|}
\hline № ח $/$ п & $\begin{array}{l}\text { Предприятие-разработчик } \\
\text { ЭКБ }\end{array}$ & $\begin{array}{c}\text { Заявленное наличие компонентов } \\
\text { с поддержкой стандартов IEEE 1149.x }\end{array}$ & $\begin{array}{c}\text { Есть данные о корректной работе } \\
\text { периферийного сканирования }\end{array}$ \\
\hline 1 & «Байкал Электроникс» & Нет & Нет \\
\hline 2 & ВЗПП-С & Да & Да \\
\hline 3 & МцСТ & Да & Да \\
\hline 4 & НИИИС им. Ю.Е. Седакова & Да & Да \\
\hline 5 & НИИСИ РАН & Да & Да \\
\hline 6 & НИиэт & Да & Да \\
\hline 7 & НПП «Цифровые Решения» & Да & Да \\
\hline 8 & НТЦ «Модуль» & да & Да \\
\hline 9 & ПКК «Миландр» & да & да \\
\hline 10 & НПЦ «ЭЛВИС» & Да & Нет \\
\hline
\end{tabular}

процесс внедрения функционала периферийного сканирования в схемотехнику ЭКБ носит эволюционный характер, и его масштабы и динамика определяются в первую очередь тем, что некоторые разработчики компонентов сами являются производителями приборов или микросборок, которые нужно тестировать.

То же можно сказать и о тестопригодной разработке плат предприятиями-приборостроителями. Очень часто платы разрабатываются без учета возможности дальнейшего тестирования и диагностики изделий на производстве. Нередки случаи применения в изделиях микросхем с поддержкой стандарта IEEE 1149.1, однако без обеспечения доступа тестирующего оборудования к интерфейсу JTAG. Роль одного из факторов, стимулирующих полноценное внедрение технологии JTAG в практику производителей электронных устройств, может сыграть отечественный стандарт по тестопригодности цифровых изделий, который сейчас разрабатывается в инициативном порядке группой специалистов, занимающихся созданием системы «ЭКБ Маркет». Применение такого стандарта в целом поможет повысить эффективность разработки и производства электроники, снизив затраты на всех этапах жизненного цикла изделий, повысив их надежность и срок службы.

Необходимо также ввести преподавание технологии периферийного сканирования в вузах. На сегодняшний день на территории Российской Федерации есть только один вуз, который занимается подобной работой, - Самарский университет. В этом учебном заведении на кафедре электротехники организованы лаборатория для студентов и курсы подготовки для сотрудников предприятий радиоэлектронной отрасли, проводятся работы по созданию внутренних стандартов предприятий по тестопригодному проектированию с учетом периферийного сканирования.

\section{ЛИТЕРАТУРА}

1. Городецкий А., Курилан Л. Введение в технологию граничного сканирования // Производство электроники: технологии, оборудование, материалы. 2007. С. 74-78.

2. Parker K.P. The boundary-scan handbook second edition. Kluwer academic publishers. 2002. 288 p.

3. IEEE Standard for Test Access Port and Boundary-Scan Architecture, IEEE Standard 1149.1-2013, The Institute of Electrical and Electronics Engineers, Inc. 3 Park Avenue, New York, NY 10016-5997, USA. 2013.

4. Гречишников В., Курицкий А., Бутько А., Иванов А. Периферийное сканирование в учебном процессе и не только: JTAG-лаборатория в Самарском университете // ЭЛЕКТРОНИКА: Наука, Технология, Бизнес. 2019. № 3. С. 120-123.

5. Гречишников В. М., Курицкий А. А. Современные технологии диагностирования многослойных печатных плат с использованием JТАG-интерфейса. - Самара: Уип Самарского государственного аэрокосмического университета, 2013. 
18-я МЕЖДУНАРОДНАЯ В ЫСТАВКА ЭЛЕКТРОНИКИ
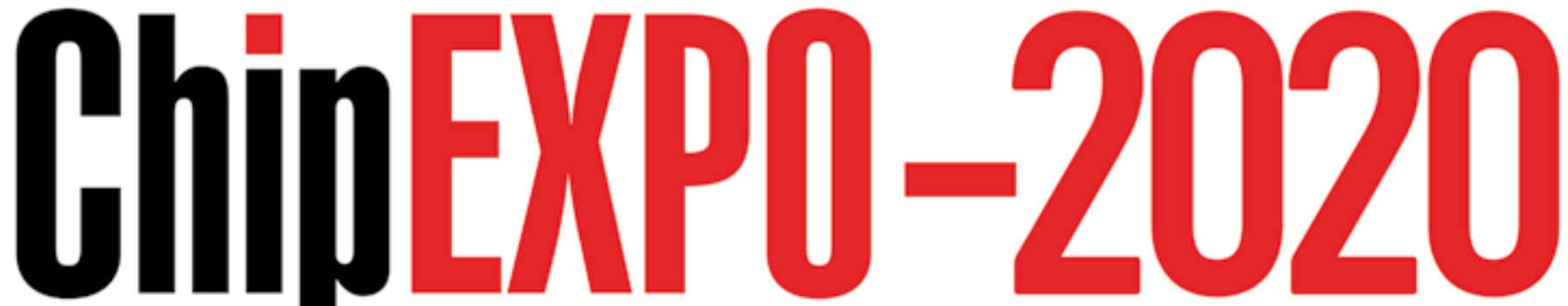

\section{КОМПОНЕНТЫ | ОБОРУДОВАНИЕ | ТЕХНОЛОГИИ}

\section{ВЫСТАВКА ПРОЙДЕТ}
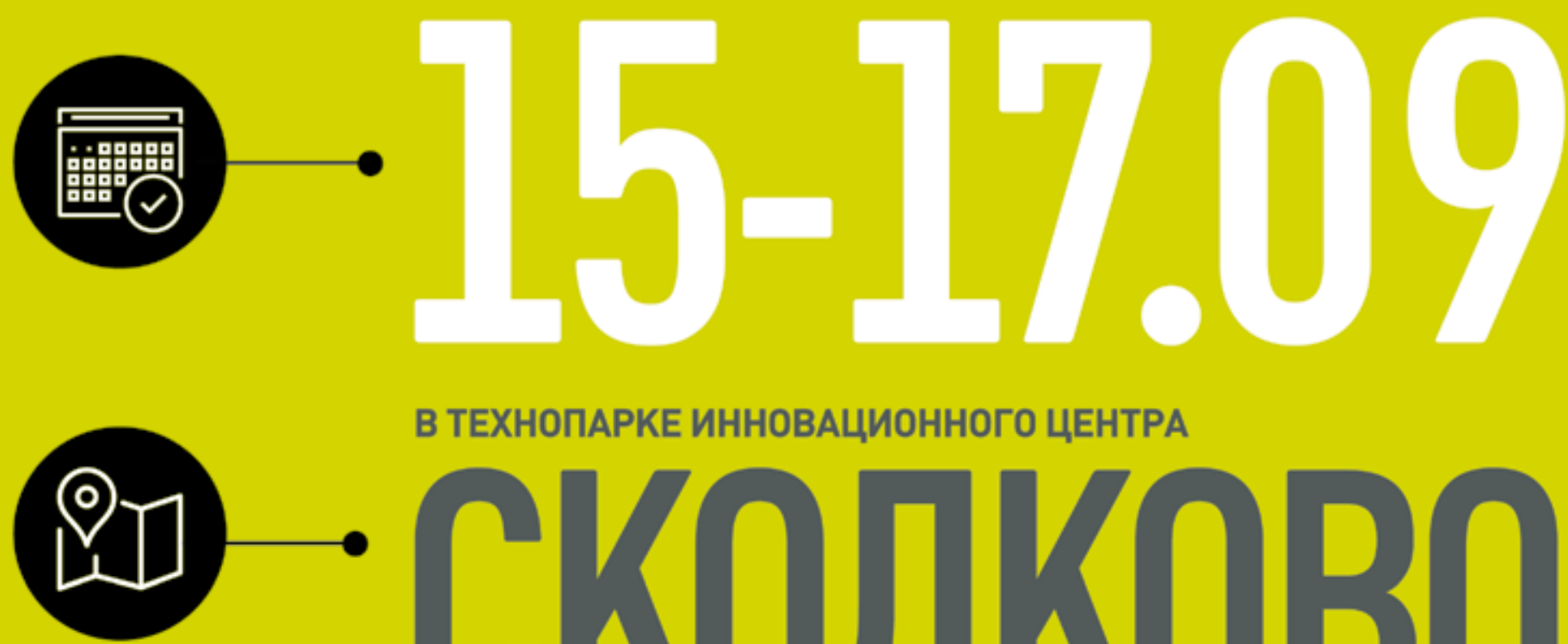

\section{В ТЕХНОПАРКЕ ИННОВАЦИОННОГО ЦЕНТРА}
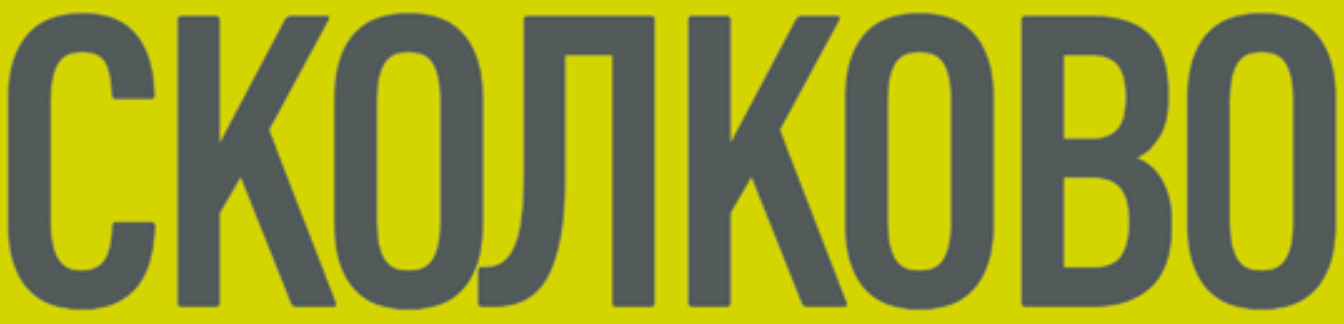

\section{ТЕМАТИЧЕСКИЕ ЭКСПОЗИЦИИ:}

- Экспозиция Департамента радиоэлектронной промышленности Минпромторга России, включая:

- экспозицию предприятий, являющихся изготовителями изделий, включенных в единый реестр российской радиоэлектронной продукции (Постановление Правительства РФ №878), - экспозицию разработок, созданных в рамках государственной программы

«Развитие электронной и радиоэлектронной промышленности на 2013-2025 годы»

[Постановление Правительства РФ №109],

- экспозицию разработок, обеспечивающих выполнение приоритетных национальных проектов.

- Дивизионы кластера

«Радиоэлектроника» ГК «Ростех»

- Стартапы в электронике

- Квалифицированные поставщикии ЭКБ

- Консорциумы и дизайн-центры по электронике

- Участники конкурса «Золотой Чип»

- Корпорация развития Зеленограда

ОФИЦИАЛЬНАЯ ПОДДЕРЖКА:
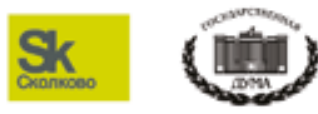

минпромторг 人 России $\mathrm{O}_{\text {росэм }}$

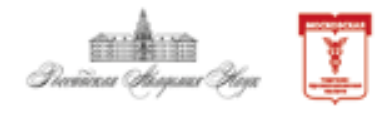

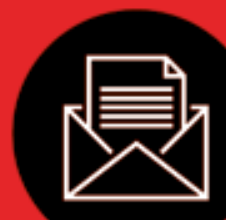

